\title{
Influence of Colostrum on the Characteristics of Ice Cream
}

\author{
Emilie Mouton, Kayanush J. Aryana* \\ School of Animal Science, Louisiana State University Agricultural Center, Baton Rouge, LA, USA \\ Email: ${ }^{*}$ karyana@agcenter.Isu.edu
}

Received 13 March 2015; accepted 31 March 2015; published 2 April 2015

Copyright (C) 2015 by authors and Scientific Research Publishing Inc.

This work is licensed under the Creative Commons Attribution International License (CC BY). http://creativecommons.org/licenses/by/4.0/

c) (i) Open Access

\begin{abstract}
Colostrum is the first milk produced by a female mammal. It is high in protein, carbohydrate and antibodies. People are constantly looking for healthier food options including immune enhancing foods. Ice cream is a popular dairy dessert and the influence of colostrum on ice cream characteristics is not known. The objective was to study the impact of various amounts of colostrum on the key attributes of ice cream. Ice creams were manufactured with $0,1.5,3.0$ and $4.5 \mathrm{~g}$ colostrum per pint $(473 \mathrm{~mL})$ of ice cream. Ice cream manufacture was replicated three times. Colostrum incorporation increased aerobic counts, apparent viscosity, but decreased meltdown resulting in slower melting of the ice creams and had no influence on flavor. In an attempt to make healthier ice creams, colostrum incorporation can be recommended in ice cream manufacture.
\end{abstract}

\section{Keywords}

\section{Ice Cream, Dairy}

\section{Introduction}

The pre-milk fluid produced from the mother's mammary glands during the first 24 to 48 hours after giving birth is called colostrum. Colostrum can be divided into immune factors and growth factors [1].

The body fights off harmful invaders such as viruses, bacteria, yeast and fungi because of the immune factors in colostrum. Over 20 pathogen specific antibodies are present in colostrum [2]. A lowered immune system function precedes or accompanies the onset on most of the infectious and degenerative diseases such as heart disease and cancer. Powerful immune factors such as immunoglobulins, lactoferrin and cytokines are present in colostrum that works to restore immune function. The mucous membranes in the bowel are the entry point for most diseases in the body. Majority of the immunoglobulins and antibodies contained in colostrum are not ab-

${ }^{*}$ Corresponding author. 
sorbed, but remain in the gastrointestinal tract where they attack pathogens before they can penetrate the body's defenses [1].

The function of growth factors is to help build and restore muscle, bone, connective tissue, nerve tissue, cartilage and skin, increase lean muscle mass, help the body burn fat for fuel, assist in wound healing and slow the signs of aging [2].

Immune factors are forty times more in bovine colostrum than human colostrum [2]. Moreover, bovine colostrum is not species-specific, which means it can also work effectively in humans and other mammals. As a person ages, the person becomes more vulnerable to disease. It takes a little longer to fight off cold or flu. Skin loses its elasticity, energy and enthusiasm lessens. Person gains unwanted weight and loses muscle tone. After maturity, humans gradually lose the immune and growth factors in the body. Aging, illness and death occur with the loss of immune and growth factors in the human body which can possibly be replaced in the human body with bovine colostrum [1] [3]. Since colostrum is a natural food, it can be consumed without experiencing side effects or drug interactions. Most colostrum manufacturers recommend and optimal intake of about $4 \mathrm{~g} /$ day of dried colostrum [2]. Whether or not colostrum influences the characteristics of ice cream is not known. The objective was to study the impact of various amounts of colostrum on the key attributes of ice cream.

\section{Materials and Methods}

\subsection{Ice Cream Manufacture}

Vanilla ice creams were manufactured according to Aryana et al., [4] and Aryana and Summers [5] with slight modification of including colostrum (colostrum powder 30\% IgG, Federal Laboratories Corp., Alden, NY, USA) separately into the ice cream mixes at $0,1.5,3.0,4.5 \mathrm{~g}$ per pint $(473 \mathrm{~mL})$ of ice cream. Control had no colostrum. The treatments/colostrum were randomly assigned to the experimental unit the milk lot. Ice cream manufacture was replicated three times.

\subsection{Aerobic Counts}

The ice creams were serially diluted and prepared with buffered $0.1 \%(\mathrm{w} / \mathrm{v})$ peptone water (Difco, Detroit, MI, USA). A number of aerobic counts were determined by plating the ice cream mixes on aerobic count petrifilm and incubating for $48 \mathrm{~h}$ at $32^{\circ} \mathrm{C}$. Three replications were conducted.

\section{3. $\mathrm{pH}$}

An Orion pH meter, model 250 A/610 (Fisher Scientific, Instruments, Pittsburgh, PA), was calibrated using pH 4.00 and 7.00 buffers (Fisher Scientific). The $\mathrm{pH}$ of the ice cream mixes were recorded at $8^{\circ} \mathrm{C}$. The $\mathrm{pH}$ determinations were in duplicate. Three replications were conducted.

\subsection{Apparent Viscosity}

The apparent viscosity of the ice cream mixes at $8^{\circ} \mathrm{C}$ was recorded using a Brookfield DV II+ viscometer (Brookfield Engineering Lab, Inc. Stoughton, MA, USA) with a helipath stand. The RV \#2 spindle was rotated at $50 \mathrm{rpm}$ and the data was recorded using Wingather software (Brookfield Engineering Labs, Inc., Stoughton, MA). One hundred data points were averaged per replication. Three replications were conducted.

\subsection{Meltdown}

At $22^{\circ} \mathrm{C}, 100 \mathrm{~g}$ of ice cream was put on a wire gauge $\left(6 \mathrm{wires} / \mathrm{cm}^{2}\right)$. The ice cream melted through the wire was collected in a graduated cylinder. The volume collected within the first hour was measured. Three replications were conducted.

\subsection{Sensory Evaluation}

A panel of seven experienced members conducted sensory evaluations on the ice creams in coded containers with random, three digit codes. A, 1 - 10 point scale was used for flavor with 10 being no criticism The official American Dairy Science Association (ADSA) Intercollegiate Dairy Products Evaluation Contest score card was 
used. Three replications were conducted.

\subsection{Statistical Analysis}

The data were analyzed by ANOVA using the PROC MIXED of Statistical Analysis Systems [6]. The means were separated using the LSD test. Differences were established at $\alpha=0.05$.

\section{Results and Discussion}

The aerobic counts are reported in Figure 1. The ice creams with colostrum had significantly higher aerobic counts that the control. With an increase in colostrum up to $3.0 \mathrm{~g} / \mathrm{pint}$ of ice cream the aerobic counts increased. Microorganisms are known to be associated with milk powders. Microbial content of milk powders is one of the criteria that influence grading of milk powders [7]. Colostrum was added in form of colostrum powder which was also source of microorganisms, hence an increase in colostrum used resulted in increase in aerobic counts. Although there was an increase in aerobic counts, the counts were within the legal limits for ice cream [8].

The $\mathrm{pH}$ values are shown in Figure 2. Use of $4.5 \mathrm{~g}$ of colostrum resulted in significantly lower $\mathrm{pH}$ compared to control. This may be because colostrum powder used had 23\% lactose (manufactures specification) hence the ice cream mixes with the most amount of colostrum would have had more lactose compared to the control (no colostrum). Within the ice cream mix there are indigenous lactobacilli [9] which ferment lactose to lactic acid lowering the $\mathrm{pH}[10]$.

The apparent viscosity values are reported in Figure 3. With colostrum incorporation the apparent viscosity was significantly higher when compared to the control. By incorporating colostrum there is an increase in total solids which in turn would increase product viscosity.

Meltdown is an important characteristic in a frozen dessert like ice cream. Rapid melting is not a desirable attribute. The melt down values are reported in Figure 4. Ice creams with colostrum had a significantly lower meltdown compared to control. Ice creams with colostrum took a longer time to melt compared to control. As colostrum content increased from 1.5 to $3 \mathrm{~g}$, the meltdown values significantly decreased, after which at $4.5 \mathrm{~g}$ it seemed to have no influence on melt down. Incorporation of colostrum in ice cream manufacture would have increased its total solids, making more solids particularly proteins available for water binding [11] hence slowing down the melting rate resulting in lower meltdown values compared to control.

The flavor scores are reported in Figure 5. There were no differences in flavor of the colostrum ice creams compared to control. Colostrum content at the amounts studied did not influence the flavor of the ice creams. This in particular is desirable because typically in the process of making a healthier version of a product flavor should not be negatively influenced.

Although incorporation of colostrum will make a small marginal increase in cost per pint of ice cream (based on production volumes and sales), it is not seen as a major limiting factor.

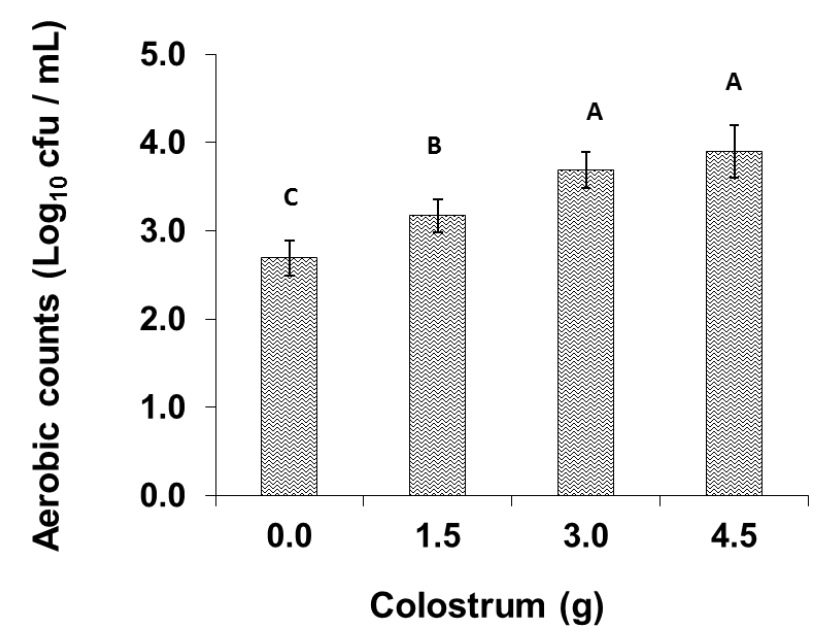

Figure 1. Total aerobic counts of the various ice creams. 


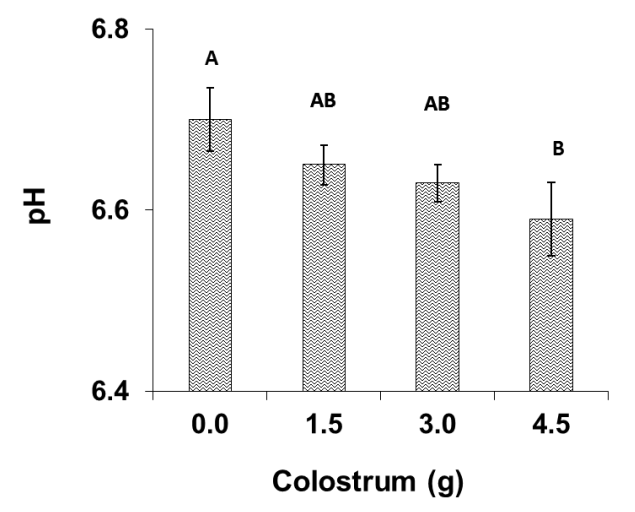

Figure 2. The $\mathrm{pH}$ of the various ice creams.

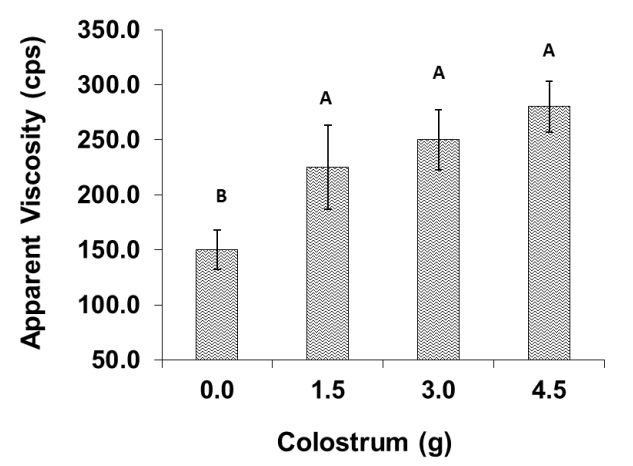

Figure 3. Apparent viscosities of the various ice creams.

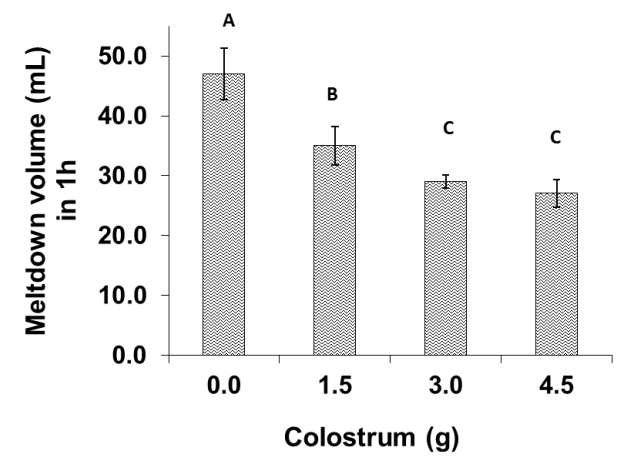

Figure 4. Meltdown volume in $1 \mathrm{~h}$ of the various ice creams.

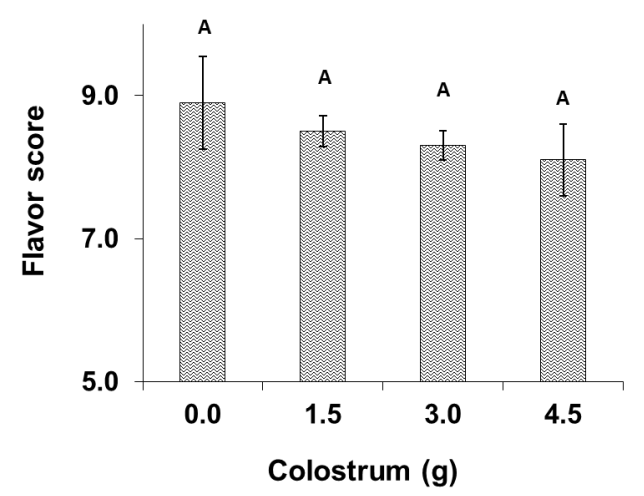

Figure 5. Flavor scores of the various ice creams. 


\section{Conclusion}

Colostrum incorporation increased aerobic counts, apparent viscosity, but decreased meltdown resulting in slower melting of the ice creams and had no influence on flavor. Use of colostrum can be recommended in ice cream manufacture.

\section{References}

[1] Kelly, G.S. (2003) Alternative Medicine Review. Journal of Clinical Therapeutic, 8, 378-394.

[2] Pakkanen, R. and Aalto, J. (1997) Growth Factors and Antimicrobial Factors of Bovine Colostrum. International Dairy Journal, 7, 285-297. http://dx.doi.org/10.1016/S0958-6946(97)00022-8

[3] Playford, R.J., Macdonald, C.E. and Johnson, W.S. (2000) Colostrum and Milk-Derived Peptide Growth Factors for the Treatment of Gastrointestinal Disorders. The American Journal of Clinical Nutrition, 72, 5-14.

[4] Aryana, K.J., Olson, D., Greenbaum, A. and Boeneke, C. (2008) Quality Characteristics of a Weight Loss Ice Cream. Milk Science International, 63, 182-185.

[5] Aryana, K.J. and Summers, M. (2006) Probiotic, Fat Free, No Sugar Added Ice-Cream. Milk Science International, 61, 184-187.

[6] Statistical Analysis Systems (2002) SAS Version 9.1. SAS Institute Inc., Cary.

[7] USDA (2001) United States Standards for Grades of Non Fat Dry Milk (Spray Process). http://www.ams.usda.gov/AMSv1.0/getfile?dDocName=STELDEV3004466

[8] FDA (2011) Grade A Pasteurized Milk Ordinances. http://www.fda.gov/downloads/Food/FoodSafety/Product-SpecificInformation/MilkSafety/NationalConferenceonInters tateMilkShipmentsNCIMSModelDocuments/UCM291757.pdf

[9] Boor, K.J. and Murphy, S.C. (2002) Microbiology of Market Milks in Dairy Microbiology Handbook, The Microbiology of Milk and Milk Products. 3rd Edition, John Wiley and Sons Inc., New York, 91-122. http://dx.doi.org/10.1002/0471723959.ch3

[10] Kosikowski, F.V. (1982) Cheese and Fermented Milk Foods. 2nd Edition, F. V. Kosikowski, Ithaca.

[11] Aryana, K.J., Haque, Z.Z. and Gerald, P.D. (2002) Influence of Whey Protein Concéntrate on the Functionality of Egg White and Bovine Serum Albumin. International Journal of Food Science and Technology, 37, 643-652. http://dx.doi.org/10.1046/j.1365-2621.2002.00588.x 